\title{
A PRIMAZIA DO VERBAL COMO RECURSO DE CRIAÇÃO EM QUADRINHOS DE TEMÁTICA POLÍTICA
}

\section{Eric Duarte Ferreira* Morgana Fabiola Cambrussi**}

Resumo: Analisamos a proeminência da linguagem verbal na composição de quadrinhos de temática política publicados durante o primeiro turno do pleito para presidente em 2018 no Brasil. Partimos de uma relação intertextual estabelecida entre uma série de quatro quadrinhos e a campanha publicitária "Agro é tech, Agro é pop, Agro é tudo" (AGRONEGÓCIO, 2016) para evidenciarmos como os recursos de paralelismo sintático, metáfora, aliteração, composição morfológica e seleção lexical sustentam duas das propriedades constitutivas do gênero textual quadrinhos: criticidade e efeito de humor.

Palavras-chave: Quadrinhos. Linguagem verbal. Intertextualidade.

\section{INTRODUÇÃO}

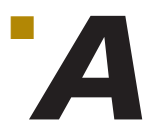

discussão proposta neste artigo concentra-se sobre as relações (inter) textuais estabelecidas entre uma sequência de quatro quadrinhos (da série Politicopatas) e a campanha publicitária "Agro é tech, Agro é pop, Agro é tudo" (AGRONEGÓCIO, 2016). Pretendemos detalhar essas relações e, ainda, avaliar o espaço ocupado pela linguagem verbal na composição dos quadrinhos, a ponto de termos a primazia desta linguagem sobre os elementos não verbais normalmente constitutivos do gênero.

Detalharemos aspectos de linguagem comumente atrelados ao gênero quadrinhos, como o hibridismo entre os códigos verbal e não verbal, com o propósito de problematizar, na produção desse gênero, o contexto em que a linguagem verbal está presente de forma exclusiva, respondendo pela essência de sua com-

\footnotetext{
* Universidade Federal da Fronteira Sul (UFFS), Chapecó, SC, Brasil. E-mail: eric@uffs.edu.br

** Universidade Federal da Fronteira Sul (UFFS), Chapecó, SC, Brasil. E-mail: morgana@uffs.edu.br
} 
posição e pela manutenção da criticidade e do efeito de humor, característicos dos quadrinhos.

Os mecanismos linguísticos que destacamos como principais recursos verbais empregados nos textos analisados, ao mesmo tempo que mantêm o seu funcionamento de acordo com as exigências do gênero quadrinhos, constituem elos para a intertextualidade verificada entre eles e a campanha publicitária. Conforme verificamos, nesse acontecimento de primazia do verbal, entram em funcionamento desde aspectos mais salientes, como estratégias de alusão, até processos gramaticais (composição morfológica, aliteração, paralelismo sintático) e semânticos (metáfora) menos aparentes, aliados à seleção lexical.

\section{A linguagem dos guadrinhos}

Ancorados na possibilidade de reflexão linguístico-textual com base na definição de hipergêneros (MAINGUENEAU, 1996, 2008), adotamos o termo quadrinhos para nomear o gênero textual a que pertencem os textos que analisamos, por duas razões principais. Primeiro porque entendemos que há livre alternância no modo como diferentes estudos se referem a textos dessa natureza (tirinhas, tiras, tiras de jornal, charge e quadrinhos, só para dar alguns exemplos), mas sem que a decisão terminológica presente nesses trabalhos deixe de se relacionar com o hiperônimo histórias em quadrinhos, para o qual quadrinhos nos pareceu uma redução bastante icônica e apropriada. Depois, porque mantemos a decisão tomada pelo periódico que publicou a série de quatro quadrinhos analisada neste artigo, o jornal Folha de S.Paulo, que utiliza o termo quadrinhos para fazer referência a textos dessa natureza.

Frequentemente, a linguagem empregada em quadrinhos é adjetivada como híbrida (LINS, 2002). Essa metáfora da "mistura do código" dos quadrinhos deriva da mescla entre palavra e imagem ou entre linguagem verbal e não verbal, considerada uma característica em sua composição. Esse hibridismo é tão reforçado como elemento de composição do gênero que até mesmo se consideram os quadrinhos "[...] como um gênero em que a união dos textos verbal e não verbal fornece pistas para a construção do sentido [...]" (SOUSA, 2011, p. 1), ou seja, a estética, a semântica, a sintaxe e a pragmática dos quadrinhos podem ser atreladas ao hibridismo do código que os compõe.

Nessa perspectiva, Viana (2012, p. 45) assume que o gênero ocorre justamente pela interação entre as duas linguagens e "[...] é constituído por uma narrativa gráfico-visual aliada à linguagem verbal [...]". Podemos observar que essas avaliações dão conta de uma posição teórica em torno do gênero quadrinhos que sustenta um peso para elementos não verbais em sua composição maior que aquele sugerido para os elementos verbais. Quando consideramos, por exemplo, que a narrativa dos quadrinhos é gráfico-visual e esta narrativa se alia a elementos verbais, estamos desequilibrando o sistema de valoração dos códigos empregados no hibridismo que se assume para a composição dos quadrinhos e reconhecendo que a base desse sistema é, na verdade, o não verbal.

Mesmo posições mais relativizadas tendem a supervalorizar o hibridismo de linguagem, como a de Lins e Gonçalves (2017, p. 163), que consideram que “[...] os textos em quadrinhos operam numa relação de complementaridade entre o visual e o linguístico [...]". Nota-se que as autoras, ainda que articulem uma 
ideia de complementariedade de códigos, tomam o caráter híbrido desses textos como um elemento presente a priori em sua composição.

Parece-nos evidente que quadrinhos são textos fortemente dependentes de uma linguagem gráfica e que a regra generalizada para sua composição é a de emprego de uma linguagem híbrida. Entretanto, podemos ver emergir processos criativos em que a produção de sentidos do texto não ocorre pelas linguagens que se mesclam, nem pela primazia de um projeto gráfico-visual que suplante a linguagem verbal. Diferente disso, quebrando as expectativas que se tem em torno da composição do gênero quadrinhos, é possível abdicar da linguagem não verbal e estruturar o gênero também pela primazia do verbal.

Quando isso acontece, pretendemos argumentar que ocorre uma quebra de expectativa para o leitor: ao acionar seu conhecimento acerca do gênero, ele precisa reanalisar a constituição e a funcionalidade de um quadrinho cujo projeto gráfico-visual, se houver, centra-se em torno da elaboração da grafia, com estilização da fonte empregada no registro verbal, mas sem outros elementos de ordem visual (nada além de palavras). Pelos textos em circulação, parece ser o caso que quadrinhos exclusivamente verbais são muito menos frequentes que quadrinhos exclusivamente não verbais. Por essa razão, na composição da série de quadrinhos que analisamos, não é apenas o fato de o hibridismo de linguagem não ser empregado que nos chama a atenção, mas também o fato de o código selecionado ser o verbal, e não o projeto gráfico-visual comumente explorado quando o hibridismo de linguagem não está presente.

Essa constatação deu origem à questão de investigação que levantamos. Pretendemos detalhar quais são os recursos linguísticos empregados na série de quadrinhos analisada que permitiram abdicar do hibridismo de linguagem e da narrativa gráfico-visual em nome da primazia de uma narrativa essencialmente verbal, mas sem provocar uma descaracterização dos quatro textos quanto ao gênero a que pertencem. Ainda que sejam textos essencialmente verbais, são quadrinhos e mantêm, além da criticidade, o efeito de humor.

Essas características estão entre as principais listadas para a constituição do gênero quadrinhos e costumam ser reforçadas pelo código não verbal (RAMOS, 2007; LINS, 2002; LINS; GONÇALVES, 2017). Na série analisada, diferentemente, a crítica e o humor vêm pela palavra, pela elaboração do verso, da figura, da analogia verbal, conforme argumentaremos nas seções seguintes.

\section{O MATERIal de ANÁlise}

Neste artigo, analisamos a intertextualidade entre uma série de quatro quadrinhos e uma campanha publicitária. Esse material de análise está disponível para acesso via internet e pode ser localizado por meio dos links informados em suas referências, ao final deste artigo. No corpo do trabalho, diferentemente, optamos pela descrição dos elementos que estamos focando em cada texto, apresentados nos quadros a seguir e retomados nas seções subsequentes. $O$ Quadro 1 detalha, além da frase principal, as três frases secundárias que compõem a campanha publicitária identificada como texto-fonte, por ser o texto retomado na intertextualidade com os quadrinhos. 
Quadro 1 - Descrição de partes da campanha veiculada pelo Grupo Globo (2016) ${ }^{1}$

\begin{tabular}{|l|l|}
\hline Frase principal: & $\begin{array}{l}\text { Agro } \\
\text { A indústria-riqueza do Brasil }\end{array}$ \\
\hline Frase secundária 1 & Agro é tech. \\
\hline Frase secundária 2 & Agro é pop. \\
\hline Frase secundária 3 & Agro é tudo. \\
\hline
\end{tabular}

Fonte: Elaborado pelos autores com dados extraídos de Agronegócio (2016).

Essa campanha (premiada em 2017 pela Sociedade Nacional de Agricultura) circulou de 2016 a 2018 e foi produzida pelas gerências de Marketing e de Comunicação da Rede Globo, segundo informações de um portal de notícias do próprio Grupo Globo (AGRONEGÓCIO, 2016). Entende-se que o propósito da campanha era o de trazer à tona a importância do agronegócio para todas as esferas da sociedade brasileira, destacando-se desde o seu valor econômico, com a geração de emprego e de renda, até o seu valor estratégico pelo abastecimento de alimentos e de matéria-prima para produtos industrializados - o que conduziria à constatação de que este setor é fundamental para o desenvolvimento do país.

Já a sequência de quatro quadrinhos descrita nos quadros de 2 a 5 foi publicada no jornal Folha de S.Paulo, durante o primeiro turno das eleições presidenciais brasileiras de 2018, como parte da série Politicopatas, de autoria do quadrinista Celso José Marques Junior. Os quadrinhos são produzidos em quadro único. Em cada um deles, emerge como personagem-tema uma figura política entre aqueles que, no momento, eram os candidatos à presidência da república com maior percentual das intenções de voto. No Quadro 2 está descrito o quadrinho cuja personagem-tema é Jair Messias Bolsonaro; no Quadro 3, José Alckmin; no Quadro 4, Fernando Haddad; e no Quadro 5, Ciro Gomes.

\section{Quadro 2 - Descrição do Quadrinho 1 de Marques Junior (2018a)²}

\begin{tabular}{|l|l|}
\hline $\begin{array}{l}\text { Texto inicial em letras menores, } \\
\text { caixa-alta, fonte em cor branca }\end{array}$ & $\begin{array}{l}\text { Bolsonaro não é agro, é ogro. } \\
\text { Ogro: a dúbia riqueza do Brasil. }\end{array}$ \\
\hline $\begin{array}{l}\text { Texto central, em destaque, letras } \\
\text { maiores e graficamente trabalhadas, } \\
\text { em cor branca }\end{array}$ & Bolso é ogro. \\
\hline $\begin{array}{l}\text { Texto final em letras menores, } \\
\text { caixa-alta, fonte em cor preta } \\
\text { (cor de fundo do quadrinho: verde) }\end{array}$ & $\begin{array}{l}\text { Bolsonaro é ogro casca-grossa. É camuflado } \\
\text { verde-claro. Bolsonaro tá no disparo. Tá no } \\
\text { ignaro e no amaro. Ogro é tech? Ogro é } \\
\text { pop? Ogro é tudo? E agora??? }\end{array}$ \\
\hline
\end{tabular}

Fonte: Elaborado pelos autores.

1 Neste quadro, descrevemos a campanha publicitária, citando seu texto de acordo com as normas técnicas vigentes. Para conhecer o material e seu funcionamento, é possível acessar o vídeo disponível em: http://g1.globo.com/economia/agronegocios/agro-a-industria-riqueza-do-brasil/noticia/2016/10/agronegocio-e-valorizado-em-campanha-da-rede-globo.html. Acesso em: $1^{\circ}$ abr. 2019.

2 Nos quadros de 2 a 5 descrevemos os quadrinhos em série analisados neste artigo. É citado o texto dos quadrinhos de acordo com as normas técnicas vigentes. Para conhecer o material e seu funcionamento, é possível acessar os links informados na lista de referências, em Marques Junior (2018a, 2018b, 2018c, 2018d). Esses links estavam ativos em $1^{\circ}$ de abril 2019. 
Quadro 3 - Descrição do Quadrinho 2 de Marques Junior (2018b)

\begin{tabular}{|l|l|}
\hline $\begin{array}{l}\text { Texto inicial em letras menores, } \\
\text { caixa-alta, fonte em cor verde }\end{array}$ & $\begin{array}{l}\text { Alckmin é chuchu. } \\
\text { O chuchu-beleza-riqueza do Brasil. }\end{array}$ \\
\hline $\begin{array}{l}\text { Texto central, em destaque, letras } \\
\text { maiores e graficamente trabalhadas, } \\
\text { em cor verde }\end{array}$ & Chuchu é agro. \\
\hline $\begin{array}{l}\text { Texto final em letras menores, caixa-alta, } \\
\text { fonte em cor verde } \\
\text { (cor de fundo do quadrinho: verde-claro) }\end{array}$ & $\begin{array}{l}\text { Alckmin tá no alecrim, no capim, na } \\
\text { trepadeira chinfrim. } \\
\text { Tá no rin tin tin, no tintim por tintim, } \\
\text { no pó de pirlimpimpim. } \\
\text { No boletim da educação mirim: só nota } \\
\text { ruim. } \\
\text { Alck é tech. Alck é min. Tá no fim? }\end{array}$ \\
\hline
\end{tabular}

Fonte: Elaborado pelos autores.

Guadro 4 - Descrição do Quadrinho 3 de Marques Junior (2018c)

\begin{tabular}{|l|l|}
\hline $\begin{array}{l}\text { Texto inicial em letras menores, } \\
\text { caixa-alta, fonte em cor vermelha }\end{array}$ & $\begin{array}{l}\text { Haddad é capacho. } \\
\text { O capacho-ardileza do Brasil. }\end{array}$ \\
\hline $\begin{array}{l}\text { Texto central, em destaque, letras } \\
\text { maiores e graficamente trabalhadas, em } \\
\text { cor vermelha }\end{array}$ & Haddad é agro simulacro. \\
\hline $\begin{array}{l}\text { Texto final em letras menores, caixa-alta, } \\
\text { fonte em cor vermelha } \\
\text { (cor de fundo do quadrinho: vermelha e } \\
\text { branca) }\end{array}$ & $\begin{array}{l}\text { Haddad é poste, mas há quem goste. } \\
\text { É pau-mandado, um Dilmo piorado. } \\
\text { cambalacho com o populacho. Com o o no esculacho, tá no } \\
\text { chefe na prisão, é dele o triplex "petrolão- } \\
\text { mensalão-corrupção". Haddad é parça. } \\
\text { Haddad é comparsa. Tá na farsa. }\end{array}$ \\
\hline
\end{tabular}

Fonte: Elaborado pelos autores.

Guadro 5 - Descrição do Quadrinho 4 de Marques Junior (2018d)

\begin{tabular}{|l|l|}
\hline $\begin{array}{l}\text { Texto inicial em letras menores, } \\
\text { caixa-alta, fonte em cor preta }\end{array}$ & $\begin{array}{l}\text { Ciro é nervosinho. } \\
\text { O nervético-riqueza do Brasil. }\end{array}$ \\
\hline $\begin{array}{l}\text { Texto central, em destaque, letras } \\
\text { maiores e graficamente trabalhadas, em } \\
\text { cor vermelha }\end{array}$ & Ciro é sacro. \\
\hline $\begin{array}{l}\text { Texto final em letras menores, caixa-alta, } \\
\text { fonte em cor vermelha } \\
\text { (cor de fundo do quadrinho: vermelha } \\
\text { e branca) }\end{array}$ & $\begin{array}{l}\text { Ciro é santo milagreiro: vai multiplicar o } \\
\text { dinheiro. Ciro arrasa: é astro do SPC- } \\
\text { Serasa. Ciro tá no ouriço, no enguiço, } \\
\text { no rebuliço. E como tá roliço! Ciro } \\
\text { demooora... Ciro chora: tá quase fora. }\end{array}$ \\
\hline
\end{tabular}

Fonte: Elaborado pelos autores. 
Apreende-se, do texto dos quadrinhos, que a perspectiva crítica é adotada para a abordagem de todos os personagens-tema, o que reforça a ideia de que, do ponto de vista do quadrinista, o interesse de produção do quadrinho não recai sobre a promoção de alguma das campanhas eleitorais, mas sobre a promoção do debate acerca de todas elas, de suas propostas e de seu contexto político-partidário. Ainda cabe ressaltar que a sequência em que os quadrinhos são aqui citados e analisados é a mesma em que foram publicados no periódico on-line. A seguir, passamos à explicitação e à análise de recursos linguísticos empregados para a composição dos quadrinhos.

\section{LINGUAGEM VERBAL COMO INDÚSTRIA-RIgUEZA DOS SENTIDOS NOS GUADRINHOS}

Após apresentarmos o material de análise que constitui nosso corpus e, ainda, qual a nossa questão de estudo quanto ao não hibridismo de linguagem nos quadrinhos da série investigada, passaremos à discussão de certos recursos linguísticos empregados na composição desses textos (alusão, paralelismo sintático, metáfora, aliteração, composição morfológica e seleção lexical). Nossa percepção quanto ao processo de criação dos quadrinhos é a de que esses recursos linguísticos tiveram dupla função: ao mesmo tempo que favoreceram a primazia da linguagem verbal na composição dos quadrinhos, também formaram elos para a intertextualidade existente entre eles e o texto-fonte.

\section{O peso do intertexto - a alusão no material de análise}

A leitura de um texto, como todo leitor iniciado já deve ter vivenciado, com frequência nos conduz a outros textos, numa atividade de remissão nem sempre consciente, em que relações entre textos se delineiam. Essas relações são intertextuais, são evocações da própria natureza da intertextualidade, formadora de processos como o de derivação textual. Ao apresentarem tais relações, Koch, Bentes e Cavalcante (2007) nos lembram que a intertextualidade se efetiva por meio do compartilhamento de elementos entre textos, o que nos permite identificar um texto em outro por meio também de gestos de familiaridade estabelecidos entre eles.

Como parte desse aparelhamento, a alusão é um recurso de intertextualidade pelo qual enunciados orientam a percepção de que se relacionam com um texto-fonte; essa percepção precisa ser ativada (não é dada de modo explícito na alusão) e apenas se efetiva quando os interlocutores conhecem o texto-fonte (KOCH; BENTES; CAVALCANTE, 2007, p. 123), muito embora a intertextualidade enquanto fenômeno textual não deixe de existir por não ter sido identificada no processo de compreensão de um texto, como vemos:

Vale ressaltar que é imperativo, numa análise intertextual em sentido restrito, a co-presença de textos, que pode ser reconhecida ou não pelo interlocutor, mas que se refere a um já-dito, portanto, a algo preexistente, denominado intertexto, o qual é apreendido por marcas linguísticas [...] (ARAÚJO; LOBO-SOUSA, 2009, p. 570).

Ao colocarmos a intertextualidade como independente do reconhecimento dos interlocutores, estamos reiterando que o fenômeno existe pelas relações de familiaridade entre textos distintos, não pela percepção dessas relações. Entre- 
tanto, a efetivação da intertextualidade, ou seja, a sua elaboração enquanto elemento constitutivo do texto, depende de ela ser identificada pelos interlocutores.

Por não se valer de recursos de referenciação ou mesmo de repetição que possam tornar a intertextualidade explícita, a alusão compõe um cenário textual em que certas diretrizes deixadas na materialidade do texto conduzem para a percepção das relações intertextuais e das similaridades registradas entre determinado texto e outro, tido como texto-fonte. Se voltarmos o olhar para nosso material de análise, podemos perceber que a série de quatro quadrinhos se constitui também pela alusão à campanha publicitária "Agro é tech. Agro é pop. Agro é tudo" (AGRONEGÓCIO, 2016); essa alusão está configurada, por assim dizer, de acordo com um conjunto de diretrizes.

Em primeiro lugar, uma gama de recursos linguísticos suscita a evocação do texto-fonte da campanha, como discutiremos em detalhe nas seções seguintes. Esses recursos vão desde processos semânticos ou sintáticos mais abstratos, como é o caso, respectivamente, da metáfora e do paralelismo, até relações fonológicas mais explícitas, como as rimas e aliterações. Ainda, diretrizes mais sutis podem ser traçadas quando processos morfológicos muito particulares (composição de palavras) reforçam elos entre os quadrinhos e o texto da campanha.

Para além das marcas efetivamente linguísticas, também podemos tomar como ponto de possivel percepção de alusão ao texto-fonte o fato de os quadrinhos reproduzirem um projeto gráfico que remete à campanha publicitária. A identidade visual, nesse caso, ocorre entre o modo de se grafar, no texto-fonte, a redução "agro" e, nos quadrinhos, a frase central que compõe o texto em destaque (nos quadros de 2 a 5, citada na linha do meio). Esse elemento é o único acontecimento da ordem do não verbal que coloca o material de análise em relação. Claramente, a identidade visual entre os quadrinhos e a campanha é um elemento de conexão intertextual, mas acaba suplantada pelo fato de a série de quadrinhos ser concebida essencialmente pela linguagem verbal.

Como pretendemos comprovar nas próximas seções, estruturas linguísticas são a base da intertextualidade entre os quadrinhos e a campanha, tornando-se as diretrizes para a alusão à publicidade e para a manutenção dessas conexões entre textos. Desse ponto de vista, pode-se argumentar que a primazia do verbal na constituição da série de quadrinhos é motivada pela decisão de intertextualidade (primeiro pela decisão de se ter uma série intertextual e, depois, pela escolha do texto-fonte), que levou à estruturação fundamentalmente verbal do intertexto entre quadrinhos e publicidade.

\section{Paralelismo sintático como elo do intertexto}

A construção de paralelismo sintático entre os períodos que compõem o texto-fonte e parte dos períodos em evidência nos quadrinhos é uma forte conexão estrutural para manutenção da intertextualidade. Via de regra, o emprego de paralelismo é um ponto de análise textual que não extrapola a materialidade de um texto, quer dizer, normalmente, discute-se se há paralelismo ou assimetria sintática entre elementos coordenados em uma mesma sequência textual, dentro dos limites postos pela unidade do texto. Isso ocorre até mesmo pelo entendimento que se tem de que paralelismo compreende "[...] a repetição de ideias mediante expressões aproximadas" (BECHARA, 2006, p. 644), ou seja, um recurso de formulação e de reformulação textual, não de conexão intertextual. 
Nosso material de análise, entretanto, possibilita-nos que investiguemos o paralelismo sintático entre textos distintos, que se conectam pela natureza intertextual. À medida que, nos quadrinhos, padrões de organização sintática são reproduzidos com o intuito de marcar a identidade e a continuidade das relações entre eles e o texto-fonte da campanha, surge uma identidade estrutural, marcada na organização sintática desses textos. Nesse caso, como frisamos antes, não se trata apenas de serem textos com elo intertextual, mas de se ter como efeito e como constituição dos quadrinhos uma simetria estrutural tão fortemente estabelecida em relação ao texto-fonte que a percepção dessas relações de intertexto tornam-se ainda mais acessiveis ao leitor.

A ideia de paralelismo sintático aplica-se aos contextos gramaticais em que há material linguístico correlato ou coordenado, com mesmo valor estrutural na composição sentencial e, por isso, esse material precisa ser expresso de modo equivalente em termos categoriais e sintagmáticos. Podemos tomar a sequência (1) como exemplo de assimetria, ou falta de paralelismo sintático, e a sequência (2) como exemplo desse paralelismo:

(1) O jovem deseja a conquista de sua liberdade, mas também manter as condições de assistência e de proteção que a família lhe oferece.

(2) O jovem deseja a conquista de sua liberdade, mas também a manutenção das condições de assistência e de proteção que a família lhe oferece.

Em (1), nota-se assimetria sintática pela quebra categorial do primeiro para o segundo argumento do verbo desejar, pois temos um primeiro argumento iniciado com nome deverbal (conquista) e um segundo com verbo (manter). Essa assimetria está desfeita em (2), em que ambos os argumentos de desejar estão iniciados por um nome deverbal. Uma vez que o material linguístico é coordenado nos dois casos, a manutenção da simetria sintática na organização sintagmática é uma necessidade.

Diferente do contexto de coordenação que exemplificamos, os quadrinhos dos quadros de 2 a 5 possuem construções sentenciais correlatas (não coordenadas) àquelas presentes no Quadro 1. Em outras palavras, o paralelismo sintático que identificamos não advém de coordenação entre elementos linguísticos, mas de correlação entre sentenças de diferentes textos. Podemos observar:

(3) "Agro é tech. Agro é pop. Agro é tudo" (AGRONEGÓCIO, 2016).

(4) Quadrinho 1: "Bolsonaro não é agro, é ogro. Bolso é ogro". Quadrinho 2: "Alckmin é chuchu. Chuchu é agro". Quadrinho 3: "Haddad é capacho. Haddad é agro simulacro". Quadrinho 4: "Ciro é nervosinho. Ciro é sacro" (MARQUES JUNIOR, 2018a, 2018b, 2018c, 2018d).

A correlação que evidenciamos, portanto, vem da repetição do padrão predicativo " $x$ é $y$ ", em que a estruturação sintática favorece a atribuição de propriedades a uma entidade que, em termos semânticos, é inserida em uma classe: o conjunto dos elementos que são tech, pop ou tudo; o conjunto dos elementos que são ogro, chuchu, capacho, agro simulacro, nervosinho, sacro. A identidade intertextual não vem, como se pode notar, da igualdade predicativa, mas da repetição do padrão predicativo da sentença. Justamente dessa diferença é que decorre 
nossa consideração de que o paralelismo sintático foi um dos recursos linguísticos centrais para o estabelecimento da intertextualidade no nosso material de análise, assim como a metáfora, favorecida nesse contexto gramatical, como abordamos a seguir.

\section{Metáfora como recurso semântico para explicitar o intertexto}

A organização textual para a construção da metáfora nos quadrinhos analisados parece ter sido facilitada pelo padrão sintático que destacamos anteriormente, marcado no paralelismo " $x$ é $y$ ". Em uma perspectiva conceitual da metáfora (LAKOFF; JOHNSON, 1980; LAKOFF, 1987), considera-se que a expressão metafórica faz parte da linguagem de forma regular e reflete as experiências com a linguagem e pela linguagem, influenciadas não apenas por processos cognitivos, mas também pela cultura e pela prática linguística dos falantes. A metáfora, na verdade, é tomada não como um recurso estilístico e literário, do campo do poético, mas como elemento basilar, constante e essencial para a linguagem (em qualquer manifestação linguística) e para estruturação do pensamento.

De acordo com esse modo de tratamento da metáfora, ela pode ser explicada como um recurso cognitivo corriqueiramente empregado pelos falantes para que se possa compreender algo ou elaborar um conceito a partir de outro elemento ou conceito previamente conhecidos. Nessa perspectiva, em termos estruturais, a metáfora pode ser representada em dois domínios - o domínio-fonte e o domínio-alvo (LAKOFF; JOHNSON, 1980). O domínio-fonte compreende o já-dado, ou seja, o conhecimento que vai ser a fonte da inferência metafórica, enquanto o domínio-alvo compreende o foco da operação cognitiva, sobre o qual vai incidir a (res)significação.

No caso anterior da sequência (3), o texto-fonte é marcado por três expressões metafóricas justapostas, em que o domínio-alvo agro (agronegócio) é compreendido com base nos conceitos de tech, pop e tudo. Percebe-se, nessa sequência de expressões metafóricas, a inferência de que o conceito de agro(negócio) pode ser formulado em termos de ciência, conhecimento, inovação, desenvolvimento e modernização (derivado de tech), de um elemento comum e popular, compartilhado e reconhecido (derivado de $p o p$ ), da característica de onipresença na economia do país, na vida e no dia a dia das pessoas (derivado de tudo).

De modo muito aproximado, nos quadrinhos analisados, expressões metafóricas dão conta de apresentar o conceito associado a cada personagem do cenário político por meio de domínios do conhecimento representativos dos elementos que são centrais para a compreensão desses conceitos. Vejamos como cada um deles se estrutura, sem que as interpretações de (5) a (8) esgotem essas possibilidades:

(5) Quadrinho 1 - Ideia de truculência e de militarismo: "Bolsonaro é ogro casca-grossa. É camuflado verde-claro. Bolsonaro tá no disparo".

(6) Quadrinho 2 - Ideia de inferioridade e de inexpressividade: "Alckmin é chuchu. Alckmin tá [...] na trepadeira chinfrim. [...] Tá no fim?”

(7) Quadrinho 3 - Ideia de farsa e de subserviência: "Haddad é capacho. Haddad é simulacro. Haddad é poste".

(8) Quadrinho 4 - Ideia de populismo e de prometimento imprudente: "Ciro é sacro. Ciro é santo milagreiro. [...] é astro do SPC-Serasa". 
Assim como ocorre no texto da campanha (Quadro 1), é possivel extrair da leitura dos quadrinhos o direcionamento discursivo dos conceitos associados aos elementos ressignificados pela metáfora que opera sobre eles. Em analogia, a repetição dos padrões " $x$ é $y$ ", ao mesmo tempo que mantém o caminho da intertextualidade com a campanha publicitária aberto e ativo, possibilita nos quadrinhos o acionamento de um conhecimento enciclopédico e, portanto, um conhecimento essencialmente cultural, para a interpretação metafórica da predicação. Essa operação linguística, cabe destacar, incide sobre a predicação enquanto processo semântico e enquanto recurso de interpretação, não incide sobre os predicados em si ou mesmo sobre o modo de estruturação gramatical " $x$ é $y$ ".

Isso quer dizer, por exemplo, que não existe dependência da estrutura " $x$ é $y$ " e que, por vezes, é possivel termos a estrutura " $x$ (não) é $y$ " (Bolsonaro não é agro); também podemos aplicar uma regra de localização abstrata, como em " $x$ está em y" ([Alckmin tá] no boletim da educação mirim/Haddad tá no cambalacho com o populacho/Ciro tá no rebuliço). São exemplos de flexibilização nos modos linguísticos de se estruturarem essas metáforas sem que elas deixem de ter correlação com o texto-fonte da campanha publicitária e sem que percam a marca de identidade textual que cada quadrinho mantém com os demais e que nos permite classificá-los como uma série (produções seriadas congêneres).

Além disso, precisamos evidenciar como elementos de cultura orbitam em torno das expressões metafóricas e concorrem para a compreensão dos conceitos acionados. No Quadrinho 1, é preponderante a informação das cores de camuflagem das forças armadas, além da aceitação de características que culturalmente denotam essa força (casca-grossa, ogro, disparo). Já a associação comumente feita entre pessoas apáticas e vegetais, com ênfase para a imobilidade, a letargia ou a incapacidade, é amplamente explorada no Quadrinho 2, assim como a ideia preconcebida de que chuchu é um alimento insosso.

No caso do Quadrinho 3, poste e capacho são elementos centrais para o acionamento da ideia de figurante, de pessoa sem autonomia e sem poder de decisão (que culmina em pau-mandado). Por fim, o Quadrinho 4 demanda do leitor conhecimentos prévios relativos ao caráter factivel ou não factível de propostas eleitorais, cuja exequibilidade é metaforicamente lançada ao campo místico (sacro, santo milagreiro, milagre da multiplicação [vai multiplicar o dinheiro]).

Essas associações que explicitamos compõem modelos cognitivos (LAKOFF, 1987) bastante estáveis e que estão na base de esquemas de metáfora de amplo emprego, ou seja, não são acidentais ou exclusividade dos quadrinhos em que foram empregadas, mas são recorrentes como organização metafórica para os conceitos expressos de (5) a (8).

A seguir, veremos como a aliteração também foi incorporada aos recursos linguísticos que estamos evidenciando como elos de intertextualidade para o material analisado e como modo de composição da primazia da linguagem verbal nos quadrinhos em discussão.

\section{Aliteração e identidade fonológica com o intertexto}

O recurso linguístico de aliteração é comumente empregado na linguagem literária, na composição de gêneros de maior subjetividade e com natureza rítmica acentuada, como é o caso do verso, na poesia (em parlendas, músicas e 
outros). No contexto dos quadrinhos que estudamos, não obstante, também podemos identificar a aliteração como elo entre o texto-fonte e os quadrinhos, reafirmando entre eles a intertextualidade e, ainda, reafirmando a condição seriada que se pode ver no material de análise.

Conforme sabemos, a aliteração ocorre por repetição de fonemas específicos ou por aproximação fonológica entre diferentes fonemas (nos casos em que não se repete um fonema, mas se produzem vocábulos com fonemas cujo ponto de articulação tenha similaridades). Esse recurso fonológico tem sido empregado para sugestão ou mesmo expressão acústica de certas representações linguísticas do pensamento (BECHARA, 2006). Além disso, distingue-se da rima porque a aliteração ocorre entre "[...] palavras que iniciam com o mesmo som ou grupo de sons [...]", e a rima ocorre entre "[...] palavras que terminam com sons iguais [...]" (FREITAS, 2003, p. 156). Podemos ainda considerar, no contexto da aliteração, que a identidade de fonemas pode estar no interior da palavra, conforme veremos adiante.

Observemos, pelo contraste em (9) e em (10), como ocorre aliteração entre vocábulos do texto-fonte e vocábulos do texto dos quadrinhos:

(9) Texto-fonte: agro $\rightarrow$ Quadrinhos: ogro/(simul)acro/sacro

(10) Texto-fonte: riqueza $\rightarrow$ Quadrinhos: beleza/ardileza

Os fonemas em repetição, os fonemas em aproximação e os encontros consonantais que se podem notar em (9) e em (10) criam uma identidade fonológica entre o texto da campanha publicitária e o texto dos quadrinhos que estamos abordando sob o escopo da aliteração. Essa identidade, com certeza, pode nos assegurar mais um modo de trânsito entre esses textos e de manutenção da intertextualidade ativa para o leitor.

Agora, observemos como a aliteração pode ser identificada entre os quatro quadrinhos analisados:

(11) Quadrinho 1: “Tá no disparo. Tá no ignaro e no amaro". Quadrinho 2: "Tá no rin tin tin, no tintim por tintim, no pó de pirlimpimpim". Quadrinho 3: "[...] tá no esculacho, tá no cambalacho com o populacho". Quadrinho 4: "[...] tá no ouriço, no enguiço, no rebuliço" (MARQUES JUNIOR, 2018a, 2018b, 2018c, 2018d).

O primeiro ponto que podemos destacar é a repetição fonológica entre os diferentes quadrinhos, estabelecendo-se a continuidade entre eles. Depois, é possível ver que dentro de um mesmo quadrinho a aliteração também se manifesta, seguindo uma coerência fonológica interna. Com isso, podemos destacar três diferentes níveis de aliteração costurando o material de análise: primeiro do texto-fonte para os quadrinhos, depois entre os quadrinhos e, por fim, no interior de cada um dos quadrinhos da série. Essa amplitude do recurso fonológico talvez seja a marca de expressão linguística mais proeminente entre os recursos utilizados e sua ocorrência em diferentes níveis ou camadas é proporcional ao alcance que a aliteração tem no estabelecimento das relações entre esses textos.

A rima está também presente na composição textual e intertextual, como se pode ver especialmente em (11). Temos a repetição de fonemas em fronteira de 
palavra, de modo sistemático, que se combina com a aliteração produzida pelos encontros consonantais. Ainda que rima e aliteração se complementem na composição da identidade fonológica desses textos, parece ser o caso de que a aliteração, como já dissemos, é um recurso proeminente. A seguir, veremos mais um elemento linguístico explorado nos quadrinhos analisados - a analogia de formação de palavras.

\section{Composição de palavras como morfologia para o intertexto}

A morfologia derivacional também integra o conjunto de recursos linguísticos empregado na estruturação da intertextualidade entre os quadrinhos analisados e destes em relação à campanha publicitária. O recurso morfológico explorado é a composição, bastante comum no português e mormente empregado para formação de novos adjetivos e substantivos (CARDOSO, 2015), como veremos adiante em (12), (13) e (14).

O recurso morfológico de composição de palavras é estratégico no planejamento textual por condensar em si valores gramaticais e semânticos mais adensados que aqueles verificados nos demais processos de formação de palavras, como a prefixação e a sufixação. Considera-se, à luz desse raciocínio, que “[...] compostos podem condensar uma frase, uma locução, um sintagma, dando ao texto mais agilidade e expressividade" (CARDOSO, 2015, p. 111).

Em (12) destacamos o vocábulo original, um substantivo que é sintese da argumentação construída na campanha publicitária, composto por dois elementos também substantivos (substantivo + substantivo = substantivo):

(12) Texto-fonte: indústria-riqueza

(13) Quadrinhos: chuchu-beleza-riqueza, capacho-ardileza, nervético-riqueza

(14) Quadrinho 1: casca-grossa, verde-claro

Nos quadrinhos, evidenciamos primeiro em (13) as composições que são formadas pela analogia a (12). As três palavras compostas guardam a propriedade semântica de condensar o valor argumentativo dos textos, reforçando os pontos de vista assumidos em relação ao personagem-tema de cada quadrinho. Outra similaridade em relação a (12) é a formação de compostos por dois elementos, mesmo em chuchu-beleza-riqueza, em que se tem [chuchu + beleza $]+$ riqueza, com uma coordenação de dois elementos primária e, depois, a coordenação desta formação com outro elemento, resultando no encadeamento da regra morfológica, em que uma composição é formada a partir de outra composição.

Também é possível vermos em (14) o recurso de composição, em que elementos são coordenados para a formação de adjetivos. Ainda na esteira de (12), mas diferentemente de (13), a linha semântica de relação entre as composições não é mais foco. Parece ser o caso de que os adjetivos de (14) não são tão relevantes em termos argumentativos, se considerado o contexto de produção dos quadrinhos e se esses adjetivos forem comparados aos substantivos em (12) e em (13), porque estes estão emergindo nos quadrinhos como vocábulos próprios daqueles textos, em um contexto em que a gramática está também a serviço da criticidade do quadrinho, além de carregarem uma marca intertextual muito nítida. A razão para mantermos (14) como composições em conexão com as demais resulta, portanto, da constatação do tipo de recurso morfológico escolhido - a 
composição como processo de formação de palavra - e não de alguma ligação intertextual mais explícita, como ocorre em (13).

$\mathrm{Na}$ próxima seção, vamos retomar a ideia de manutenção da criticidade pela palavra, não mais com o foco na composição de palavras, mas na seleção lexical e em seus efeitos argumentativos.

\section{Seleção lexical e argumentação}

O léxico que compõe os quadrinhos em análise reforça a argumentação desses textos porque, visto da perspectiva da textualidade, não pode ter ignorado seu potencial de construção de viés ideológico ou mesmo de persuasão. Nesses termos, assume-se que a seleção lexical de qualquer texto é estratégica e reflete as intenções desejadas quanto aos efeitos de sentido possiveis (ANTUNES, 2012).

A manutenção da coerência textual, independentemente do gênero em discussão, depende do equilíbrio entre finas relações linguísticas e extralinguísticas que vão se estabelecendo. No universo dos quadrinhos, em especial na nossa mostra de análise, não é diferente. A seleção lexical é uma das decisões que cruza esses dois fios de relações, já que os campos semânticos mobilizados pelas palavras se configuram em duas direções: uma interna, referente às relações das palavras entre si e com o projeto de texto; outra externa, relativo ao universo de associações que o próprio leitor poderá fazer a partir dos movimentos acionados por dada palavra, em seu contexto de uso. Seguindo nessa lógica, como lembra Cavalcante (2012), a coerência é um princípio de interpretabilidade que, como pretendemos mostrar à frente, sustenta-se também pela seleção lexical.

As relações estabelecidas a seguir indicam como a ideia em destaque é reforçada pelas palavras (extraídas de cada quadrinho) que a ela podem ser associadas:

(15) Quadrinho 1 - Agressividade, militarismo e força bruta: ogro, casca-grossa, camuflado verde-claro, disparo.

(16) Quadrinho 2 - Inexpressividade e insignificância: chuchu, alecrim, capim, trepadeira (ser um vegetal), (educação) mirim, (nota) ruim, fim.

(17) Quadrinho 3 - Farsa, falcatrua e sujeição: capacho, ardileza, simulacro, poste, cambalacho, comparsa, farsa.

(18) Quadrinho 4 - Descontrole emocional, instabilidade psicológica: nervosinho, nervético, chorar (chora). Ausência de viabilidade, de exequibilidade de propostas: sacro, santo milagreiro, multiplicar.

Em (15) estão alguns dos itens lexicais utilizados pelo Quadrinho 1 para a construção da imagem de truculência e a associação dessa imagem ao então candidato à Presidência da República, Jair Bolsonaro. Nota-se que os campos semânticos a que pertencem as palavras que descrevem a personagem-tema do quadrinho denotam uma filiação bélica, de força e de animosidade.

Diferentemente, (16) ilustra como parte da seleção lexical do Quadrinho 2 intenciona incorporar à imagem de outro candidato, Geraldo Alckmin, a ideia de baixa importância política e de inexpressividade na corrida eleitoral. Percebe-se que uma relação entre a imagem da personagem-tema e certos vegetais corrobora essa visão, ao termos a construção de uma personalidade inerte e limitada. 
Um terceiro viés aparece pela seleção lexical do Quadrinho 3, em que a imagem do candidato Fernando Haddad está descrita por uma seleção lexical da ordem da desonestidade, trazendo à tona o legado de corrupção a ele comumente direcionado, além da suspeição de que sua candidatura não possuiria autonomia, pois estaria sendo comandada por outra figura política. Esse cenário de fraude eleitoral está também caracterizado ideologicamente como algo ardil, ou seja, astuto e fraudulento.

Por fim, o Quadrinho 4 reforça duas características centrais de seu personagem-tema, o então candidato Ciro Gomes. Primeiro, parte da seleção lexical constrói a visão de desequilíbrio psíquico, como tentativa de fundir à visão do candidato um quadro emocional de falta de controle e de estabilidade. Depois, outro campo semântico em jogo na seleção lexical coloca em xeque a veracidade das propostas do candidato, associando a elas palavras do universo místico religioso e, portanto, não factivel.

Como afirmamos anteriormente, parte da coerência desses textos analisados está atrelada às relações semânticas que se podem delinear por meio da seleção lexical. Não são simples caracterizações de um personagem-tema, mas são posicionamentos em relação a esse tema que se deixam traduzir em palavras do universo recortado, com ideário e argumentação. Essas considerações não apenas se juntam a tantas que já apresentam o léxico (ou a seleção lexical) como importante mecanismo de argumentação, mas também reforçam nossa visão de que a primazia do verbal nos quadrinhos analisados se estruturou sobre um diversificado leque de recursos linguísticos empregados em favor da manutenção das funcionalidades desse gênero textual.

\section{CONSIDERAÇÕES FINAIS}

A reflexão que construímos em torno do material de análise nos permitiu demonstrar como elos linguísticos distintos são empregados de modo a constituírem mecanismos de estabelecimento e de manutenção de intertextualidade. Essas relações intertextuais estão aferidas, nas seções anteriores, não apenas entre os quadrinhos e o texto-fonte (a campanha publicitária), mas também entre os quatro quadrinhos estudados - o que nos permite classificá-los como uma produção seriada.

Além disso, confrontamos a ideia de linguagem híbrida intrínseca à composição de textos do gênero quadrinhos ao mostrarmos que nem criticidade nem efeito de humor, características desses textos, deixam de ser atendidas na produção dos quadrinhos com prevalência do código verbal. Além de não termos a descaracterização do gênero quadrinhos pelo fato de a linguagem empregada na série analisada estar centrada em um único código, foi possível constatarmos que esse código único é o verbal, do qual destacamos vários recursos linguísticos (paralelismo sintático, metáfora, aliteração, composição morfológica e seleção lexical) fundamentais no processo criativo desses quadrinhos e na manutenção da intertextualidade, como já dissemos.

Evidentemente, não é comum que textos do gênero quadrinhos se estruturem com linguagem essencialmente verbal, mas não podemos deixar de considerar que este é um modo de produção - assim como é possível verificarmos a ocorrência de quadrinhos essencialmente não verbais. No material analisado, 
há um projeto gráfico mínimo (cores de fonte e de fundo, tipo de fonte), mas ele não é nada além de estilização da fonte em que estão grafadas as palavras; é um projeto gráfico do código verbal. Por fim, reiteramos que nosso propósito não era o de esgotar os recursos linguísticos que foram usados em serviço da manutenção da intertextualidade e da construção da primazia do verbal em quadrinhos. Outros estudos podem, certamente, acrescentar ainda mais informações e ampliar nossa compreensão acerca desse contexto de produção.

\section{The Verbal PRIMACy as a RESOURCe FOR THE CREATION OF POLITICAL CARTOONS}

Abstract: This paper addresses how verbal language stands out as part of the composition of political cartoons during the first round of Brazil's presidential election in 2018. We based our analysis on the observation of the intertextual aspects between four political cartoons and the advertising campaign "Agro é tech, Agro é pop, Agro é tudo" (AGRONEGÓCIO, 2016), so as to highlight how sintatic paralelism, metaphors, aliteration, morphological composition and lexical choice support two of the constitutive properties which are part of the text genre political cartoon: criticity and sense of humor.

Keywords: Cartoons. Verbal language. Intertextuality.

\section{REFERÊNCIAS}

ANTUNES, I. Território das palavras: estudo do léxico em sala de aula. São Paulo: Parábola, 2012.

ARAÚJO, J. C.; LOBO-SOUSA, A. C. Considerações sobre a intertextualidade no hipertexto. Linguagem em (Dis)curso, Palhoça, v. 9, n. 3, p. 565-583, set./dez. 2009.

BECHARA, E. Moderna gramática portuguesa. 37. ed. rev. ampl. Rio de Janeiro: Lucerna, 2006.

CARDOSO, E. A. Composição. In: RODRIGUES, A.; ALVES, I. M. (org.). A construção morfológica da palavra. São Paulo: Contexto, 2015. p. 111-122. Coleção Gramática do português culto falado no Brasil (Coord. Ataliba de Castilho).

CAVAlCANTE, M. M. Os sentidos do texto. São Paulo: Contexto, 2012.

FREITAS, G. C. M. Consciência fonológica: rimas e aliterações no português brasileiro. Revista Letras de Hoje, Porto Alegre, v. 38, n. 2, p. 155-170, junho, 2003. Disponivel em: http://revistaseletronicas.pucrs.br/fale/ojs/index.php/ fale/article/view/14096/9352. Acesso em: $1^{\circ}$ abr. 2019.

AGRONEGÓCIO é valorizado em campanha da Rede Globo. G1, Rio de Janeiro, $1^{\circ}$ out. 2016. Disponivel em: http://g1.globo.com/economia/agronegocios/ agro-a-industria-riqueza-do-brasil/noticia/2016/10/agronegocio-e-valorizado-em-campanha-da-rede-globo.html. Acesso em: $1^{\circ}$ abr. 2019.

KOCH, I. G. V.; BENTES, A. C.; CAVALCANTE, M. M. Intertextualidade: diálogos possiveis. São Paulo: Cortez, 2007.

LAKOFF, G. Women fire and dangerous things: what categories reveal about the mind. Chicago: University of Chicago Press, 1987. 
LAKOFF, G.; JOHNSON, M. Metaphors we live by. London: The University of Chicago Press, 1980.

LINS, M. P. P. O humor nas tiras de quadrinhos. São Paulo: Grafer, 2002.

LINS, M. P. P.; GONÇALVES, D. W. Humor e resiliência: as implicaturas nas tiras “SuperNormais”. Percursos Linguísticos, v. 7, n. 15, p. 157-173, 2017.

MAINGUENEAU, D. Elementos de linguística para o texto literário. São Paulo: Martins Fontes, 1996.

MAINGUEneAU, D. Cenas da enunciação. São Paulo: Parábola, 2008.

MARQUES JUNIOR, C. J. Politicopatas. Folha de S.Paulo, São Paulo, 5 set. 2018a. Caderno de Cultura, Quadrinhos, Cartuns Diários. Disponivel em: https://www1.folha.uol.com.br/ilustrada/cartum/cartunsdiarios/\#5/9/2018. Acesso em: $1^{\circ}$ abr. 2019.

MARQUES JUNIOR, C. J. Politicopatas. Folha de S.Paulo, São Paulo, 8 set. 2018b. Caderno de Cultura, Quadrinhos, Cartuns Diários. Disponivel em: https://www1.folha.uol.com.br/ilustrada/cartum/cartunsdiarios/\#8/9/2018. Acesso em: $1^{\circ}$ abr. 2019.

MARQUES JUNIOR, C. J. Politicopatas. Folha de S.Paulo, São Paulo, 14 set. 2018c. Caderno de Cultura, Quadrinhos, Cartuns Diários. Disponivel em: https: / / www 1.folha.uol.com.br/ilustrada/cartum/cartunsdiarios / \#14/9/ 2018. Acesso em: $1^{\circ}$ abr. 2019.

MARQUES JUNIOR, C. J. Politicopatas. Folha de S.Paulo, São Paulo, 26 set. 2018d. Caderno de Cultura, Quadrinhos, Cartuns Diários. Disponível em: https: / /www1.folha.uol.com.br/ilustrada/cartum/cartunsdiarios /\#26/9/ 2018. Acesso em: 1 abr. 2019.

RAMOS, P. Tiras cômicas e piadas: duas leituras, um efeito de humor. 2007. 424 f. Tese (Doutorado em Letras - Filologia e Língua Portuguesa)-Universidade de São Paulo, São Paulo, 2007.

SOUSA, A. L. F. A construção de sentido no gênero quadrinhos: uma análise do fenômeno da mesclagem. In: SIMPÓSIO INTERNACIONAL DE ESTUDOS DOS GÊNEROS TEXTUAIS, 6., 2011, Natal. Anais... Natal, 2011.

VIANA, A. M. Compreensão leitora e humor de Histórias em Quadrinhos em ELE. 2012. 161 f. Tese (Doutorado em Letras Neolatinas)-Universidade Federal do Rio de Janeiro, Rio de Janeiro, 2012.

Recebido em 12 de novembro de 2018. Aprovado em 23 de março de 2019. 